OPEN ACCESS

Edited by:

Karen Nelson,

J. Craig Venter Institute (La Jolla),

United States

Reviewed by:

Maryam Dadar.

Razi Vaccine and Serum Research Institute, Iran

Jeffrey Ebersole,

University of Nevada, Las Vegas,

United States

*Correspondence:

Alexandru Movila

amovila@nova.edu

Specialty section: This article was submitted to Microbial Immunology, a section of the journal

Frontiers in Immunology

Received: 04 August 2020 Accepted: 20 October 2020 Published: 23 November 2020

Citation:

Yamada C, Akkaoui J, Ho A, Duarte C, Deth $R$, Kawai T, Nichols $F$. Lakshmana MK and Movila A (2020)

Potential Role of Phosphoglycerol

Dihydroceramide Produced by

Periodontal Pathogen Porphyromonas

gingivalis in the Pathogenesis of

Alzheimer's Disease.

Front. Immunol. 11:591571.

doi: 10.3389/fimmu.2020.591571

\section{Potential Role of Phosphoglycerol Dihydroceramide Produced by Periodontal Pathogen Porphyromonas gingivalis in the Pathogenesis of Alzheimer's Disease}

\author{
Chiaki Yamada ${ }^{1}$, Juliet Akkaoui ${ }^{1}$, Anny Ho ${ }^{1}$, Carolina Duarte ${ }^{1}$, Richard Deth ${ }^{2}$, \\ Toshihisa Kawai ${ }^{1}$, Frank Nichols ${ }^{3}$, Madepalli K. Lakshmana ${ }^{4}$ and Alexandru Movila ${ }^{1,5 *}$ \\ ${ }^{1}$ College of Dental Medicine, Nova Southeastern University, Ft. Lauderdale, FL, United States, ${ }^{2}$ College of Pharmacy, Nova \\ Southeastern University, Ft. Lauderdale, FL, United States, ${ }^{3}$ School of Dental Medicine, The University of Connecticut Health \\ Center, Farmington, CT, United States, ${ }^{4}$ Herbert Wertheim College of Medicine, Florida International University, Miami, FL, United \\ States, ${ }^{5}$ Institute for Neuro-Immune Medicine, Nova Southeastern University, Ft. Lauderdale, FL, United States
}

Background: Among different types of sphingolipids produced by human cells, the possible engagement of ceramide species in the pathogenesis of Alzheimer's disease (AD) has attracted recent attention. While ceramides are primarily generated by de novo synthesis in mammalian cells, only a limited number of bacterial species, produce ceramides, including phosphoglycerol dihydroceramide (PGDHC) that is produced by the key periodontal pathogen Porphyromonas gingivalis. Emerging evidence indicates that virulence factors produced by $P$. gingivalis, such as lipopolysaccharide and gingipain, may be engaged in the initiation and/or progression of $A D$. However, the potential role of $P G D H C$ in the pathogenesis of $A D$ remains unknown. Therefore, the aim of this study was to evaluate the influence of PGDHC on hallmark findings in AD.

Material and Methods: CHO-7WD10 and SH-SY-5Y cells were exposed to PGDHC and lipopolysaccharide (LPS) isolated from $P$. gingivalis. Soluble A 42 peptide, amyloid precursor protein (APP), phosphorylated tau and senescence-associated secretory phenotype (SASP) factors were quantified using ELISA and Western blot assays.

Results: Our results indicate that $P$. gingivalis $(P g)$-derived PGDHC, but not Pg-LPS, upregulated secretion of soluble A $\beta 42$ peptide and expression of APP in CHO-7WD10 cells. Furthermore, hyperphosphorylation of tau protein was observed in SH-SY-5Y cells in response to PGDHC lipid. In contrast, Pg-LPS had little, or no significant effect on the tau phosphorylation induced in SH-SY-5Y cells. However, both PGDHC and Pg-LPS contributed to the senescence of SH-SY5Y cells as indicated by the production of senescence-associated secretory phenotype (SASP) markers, including betagalactosidase, cathepsin B (CtsB), and pro-inflammatory cytokines TNF- $\alpha$, and IL-6. Additionally, PGDHC diminished expression of the senescence-protection marker sirtuin1 in SH-SY-5Y cells. 


\begin{abstract}
Conclusions: Altogether, our results indicate that $P$. gingivalis-derived PGDHC ceramide promotes amyloidogenesis and hyperphosphorylation, as well as the production of SASP factors. Thus, PGDHC may represent a novel class of bacterial-derived virulence factors for AD associated with periodontitis.
\end{abstract}

Keywords: Alzheimer's Disease, Porphyromonas gingivalis, dihydroceramides, amyloid precursor protein, tau protein, cellular senescence, senescence-associated secretory phenotype

\section{INTRODUCTION}

Alzheimer's disease (AD) is a multifactorial, highly heterogeneous, and complex neurodegenerative disorder that affects memory and cognitive functions leading to total dependence on nursing care at an advanced stage. Approximately 35.6 million patients are affected by $\mathrm{AD}$ worldwide and about 4.6 million new cases are added each year, causing enormous societal and economic burden $(1,2)$. It is commonly accepted that elevated amounts of aggregated $\mathrm{A} \beta$ peptides and hyperphosphorylated tau protein lead to deposition of extracellular amyloid plaques and intracellular neurofibrillary tangles in the brain of $\mathrm{AD}$ patients, making them hallmark features of $\mathrm{AD}$ neuropathology (3). The growing evidence suggests that age is the most prevalent risk factor for $\operatorname{AD}(4,5)$. Although the ageassociated gut bacterial dysbiosis is significantly correlated with the pathogenesis of $\mathrm{AD}(6)$, there is limited knowledge about the impact of oral bacteria on aging-associated AD.

The oral Gram-negative anaerobe, Porphyromonas gingivalis, is considered to be a keystone pathogen in chronic periodontitis (7$10)$. It is also well-documented that $P$. gingivalis is a contributory factor for various systemic diseases associated with aging, including type-II diabetes, and cardiovascular diseases (11). Furthermore, presence of $P$. gingivalis in $\mathrm{AD}$ brains $(12,13)$, as well as detection of elevated levels of IgG against $P$. gingivalis in periodontitis patients with $\mathrm{AD}$, implicates a potential contributory role of this periodontal bacteria in the pathogenesis of $\mathrm{AD}$ (14).

$P$. gingivalis produces a wide variety of virulence factors of lipid origin, including lipopolysaccharide (LPS) and novel sphingolipids termed phosphoglycerol dihydroceramide (PGDHC) and phosphoethanolamine dihydroceramide (PEDHC) (15). Although ligation of $P g$-LPS and PEDHC with Toll-Like Receptor (TLR) 2 and TLR4 elicits a strong inflammatory signaling induced in young mice, various published studies indicated that TLR function may be impaired in the context of aging (16-18). Furthermore, it was also recently demonstrated that P.g-LPS had little, or no, effect on the promotion of periodontitis inflammation induced in aged mice (19). We, however, reported that PGDHC ceramide promotes inflammation in a manner independent of TLRs (20), indicating that PGDHC may also represent a novel virulence risk factor that contributes to various age-related disorders, including periodontitis and AD.

Emerging evidence has indicated that among different sphingolipids, the levels of mammalian ceramide species were significantly elevated in brains of patients with more than one neuropathologic abnormality compared to the age-matched neurologically normal group of people (21). Although bacterial dihydroceramides, including those derived by $P$. gingivalis, share basic structural characteristics with mammalian ceramides, sphingolipid production by bacteria was thought to be a rare occurrence because only a limited number of gut and oral bacterial species can synthesize ceramides de novo (22-24). Nonetheless, because no studies have yet examined the role of ceramides produced by oral bacterial in the pathogenesis of $\mathrm{AD}$, it remains unclear whether $P$. gingivalis-derived $\mathrm{PGDHC}$ contributes to the onset or progression of AD. Therefore, this study aimed to evaluate the potential involvement of PGDHC in the amyloidogenic processing of amyloid precursor protein (APP), hyperphosphorylation of tau, and cellular senescence, as key features of $\mathrm{AD}$ pathogenesis.

\section{MATERIAL AND METHODS}

\section{Cell Cultures}

Chinese hamster ovary-7WD10 (CHO-7WD10) cells stably expressing human wild-type amyloid precursor protein 751 (APP751WT) were cultured in DMEM media (Corning) supplemented with $10 \%$ fetal bovine serum (FBS), 1\% penicillin/ streptomycin, and $2 \mathrm{mM}$ L-glutamine. SH-SY5Y human neuroblastoma cells were cultured in 1:1 mixture of DMEM: F12 media with the same supplements as that of CHO-7WD10 cells.

\section{PGDHC and LPS From Porphyromonas gingivalis}

PGDHC was isolated from Porphyromonas gingivalis (ATTC strain \#33277) as previously described (20). For biological experiments, PGDHC was sonicated (2 min, $3 \mathrm{~W}$ ) in phosphate-buffered saline (PBS) to achieve a concentration of $100 \mu \mathrm{g} / \mathrm{ml}$. Ultrapure $P g$-LPS was purchased from InvivoGen and prepared according to the manufacturer's recommendation.

\section{Cytotoxicity Assays}

CHO-7WD10 and SH-SY-5Y cells were seeded in a 96-well plate at a density of $1 \times 10^{4}$ cells/well and exposed to several concentrations of $P g$-LPS and PGDHC $(0,1,5,8,10 \mu \mathrm{g} / \mathrm{ml})$. After $24 \mathrm{~h}$ of incubation, WST-1 metabolic activity assay (Sigma Aldrich) was employed according to the manufacturer's instructions.

\section{Quantification of Soluble A $\beta 42$}

CHO-7WD10 cells were seeded in a 6-well plate at a density of $1 \times 10^{6}$ cells/well and cultured in the presence or absence of $\mathrm{Pg}$ LPS or PGDHC for $48 \mathrm{~h}$. Culture supernatants were collected and the amount of soluble $\mathrm{A} \beta 42$ was quantified using a commercial sandwich ELISA kit from Thermofisher. 


\section{Quantification of $\beta$-Galactosidase Activity in SH-SY-5Y Cells}

$\beta$-galactosidase activity was evaluated using a commercial senescence $\beta$-galactosidase staining kit (Cell Signalling Technology) according to the manufacturer's recommendation. Staining-patterns of cells in the culture well were acquired by a 20x objective lens using an EVOS cell imaging system under bright-field illumination.

\section{Western Blot Analysis}

CHO-7WD10 and SH-SY-5Y cells were seeded at $1 \times 10^{6}$ cells/well in a six-well plates and stimulated with various concentrations of PGDHC and Pg-LPS as listed for the cytotoxicity assay. After $48 \mathrm{~h}$ of stimulation, cells were lysed in the lysis buffer (Thermofisher) and protein concentration was measured using the BCA kit (Pierce). Next, proteins were separated using SDS/PAGE (Bolt $12 \%$ gel) electrophoresis, transferred onto a nitrocellulose (NC) membrane and blocked using iBlot2 (Thermofisher). The antimouse CT15 polyclonal antibody (1:500) (Calbiochem) was used for detection of full-length APP in CHO-7WD10.

To detect phosphorylated-Tau (p-Tau), sirtuin-1, and cathepsin B in SH-SY5Y cells, rabbit anti-p-Tau $\left(\mathrm{Ser}^{396}\right)$, and -mouse AT1000 $\left(\mathrm{Thr}^{212} / \mathrm{Ser}^{214}\right)$, - Sirt-1 and -cathepsin B polyclonal antibodies (1:1,000; Thermofisher) were used, respectively. The anti-human $\beta$ actin antibody (cat \# 1:2,000; CST) was used to detect the levels of $\beta$ actin as a loading control. Finally, the membranes were washed with tris-buffered saline (TBS) containing 0.05\% Tween 20 and then processed using horseradish peroxidase (HRP)-conjugated antirabbit or anti-mouse secondary antibodies (Amersham Pharmacia Biotech) followed by enhanced chemiluminescence detection (ThermoFisher). The signal intensity of Western blots was quantified using Image J.

\section{Real-Time PCR Analysis of Gene Expression} RNA was isolated using the PureLink ${ }^{\mathrm{TM}}$ RNA Mini Kit (Ambion, Life Technologies, USA) according to manufacturer's instructions. Altogether, $1 \mu \mathrm{g}$ of RNA was reverse transcribed with the Verso cDNA Synthesis Kit (Thermo Scientific). Gene expression was quantified using PowerUp ${ }^{\mathrm{TM}}$ Sybr $^{\mathrm{TM}}$ Green Master Mix (Applied Biosystems Diagnostics) in the AriaMx Real-time PCR System (Agilent). Data were analyzed by the $\Delta \Delta \mathrm{Ct}$ method normalized to $\beta$-actin as the internal reference gene. Primer sequences are available upon request.

\section{Statistical Analysis}

Significant differences in quantitative data were determined by one-way analysis of variance (ANOVA) followed by Tukey's posthoc test using the paleontological statistics software (PAST) version 4.02 and $p$ values $\leq 0.05$ were considered significant. The data are displayed as means \pm standard deviation (SD).

\section{RESULTS}

\section{PGDHC Enhances Secretion of Amyloid- Beta $(A \beta)$ in CHO-7WD10 Cells}

Since genetic, biochemical, and pathological evidence has strongly implicated that $A \beta$ plays an early and crucial role in $\mathrm{AD}$ pathogenesis (25), we first tested whether PGDHC in comparison to $P g$-LPS, exacerbate amyloidogenic processing of APP, using $\mathrm{CHO}$ cells stably expressing human APP751WT protein $(\mathrm{CHO}-$ 7WD10) in vitro. When the concentrations of both $P g$-LPS and PGDHC were greater than $5 \mu \mathrm{g} / \mathrm{ml}$, our results showed that the viability of CHO-7WD10 cells was significantly reduced. Thus, CHO-7WD10 cells exposed to 8 and $10 \mu \mathrm{g} / \mathrm{ml}$ of PGDHC and $\mathrm{Pg}$ LPS were excluded from the further examinations.

According to our results, exposure of $\mathrm{CHO}-7 \mathrm{WD} 10$ cells to PGDHC, but not to $P g$-LPS, significantly elevated the release of A $\beta 42$ peptide in a dose-dependent manner (Figures 1A, B). Next, to detect the level of APP using a Western blot assay, lysates were prepared from the same cells that were used for $A \beta 42$ quantitation after treatment with different concentrations of $P g$-LPS and PGDHC. Pg-LPS had no or little effects on the APP levels in CHO-7WD10 cells (Figures 2A, B). By contrast, PGDHC significantly elevated the levels of APP in CHO-7WD10 cells when compared to the control, non-treated cells (Figures 2C, D). These observations suggested that PGDHC, but not $P g$-LPS, enhances secretion of $\mathrm{A} \beta$ from $\mathrm{CHO}-7 \mathrm{WD} 10$ cells in vitro.

\section{PGDHC Induces the Site-Specific Phosphorylation of Tau (p-Tau) in SH-SY- 5Y Cells}

Because published evidence demonstrated that the hyperphosphorylation of Tau protein was significantly upregulated in the hippocampi of $\mathrm{AD}$ patients (26), we next wanted to assess the $\mathrm{p}$ Tau status in SH-SY-5Y cells exposed to various concentrations of $P g$ LPS and PGDHC using two antibodies that recognize hyperphosphorylated tau at $\mathrm{Ser}^{396}$ and $\mathrm{Thr}^{212} / \mathrm{Ser}^{214}$ sites by Western blot assay. We observed that p-Tau at Ser ${ }^{396}$ was significantly increased after treatment with PGDHC when compared to control cells (Figures 3A, B). Furthermore, PGDHC also significantly upregulated $\mathrm{p}$-Tau at $\mathrm{Thr}^{212} / \mathrm{Ser}^{214}$ in a dose-dependent manner compared to the control cells (Figures 3C, D). However, $\mathrm{Pg}$ LPS did not induce p-Tau at either $\mathrm{Ser}^{396}$ or $\mathrm{Thr}^{212} / \mathrm{Ser}^{214}$ loci in SHSY-5Y cells (Figures 3A-D). These results indicate that PGDHC may
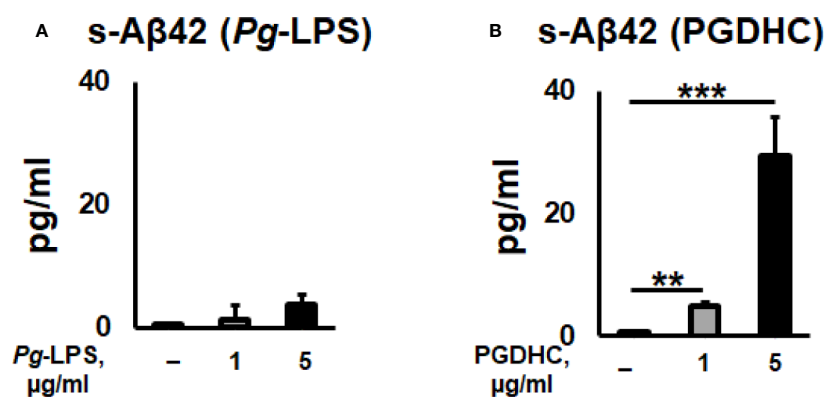

FIGURE 1 | Porphyromonas gingivalis-derived phosphoglycerol dihydroceramide (PGDHC) promotes $A \beta-42$ secretion from Chinese hamster ovary $(\mathrm{CHO})$ cells stably expressing human wild-type amyloid precursor protein 751 protein (CHO-7WD10). CHO-7WD10 cells were exposed to different concentrations of Pg-LPS (A) or PGDHC (B) for $48 \mathrm{~h}$. Then, the conditioned media were collected and analyzed by ELISA. $\mathrm{N}=4$ samples/ condition. ${ }^{* \star} p<0.01,{ }^{* \star *} p<0.001$ 


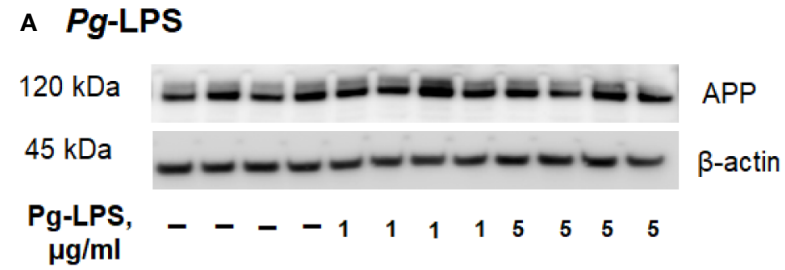

C PGDHC

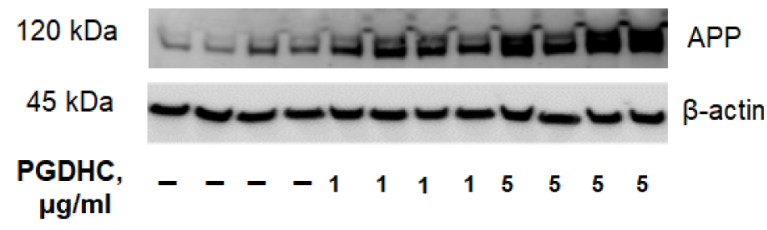

B Pg-LPS

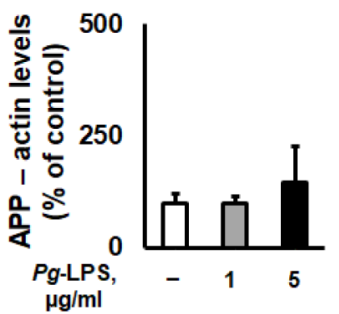

D PGDHC

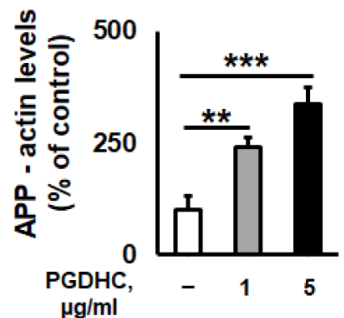

FIGURE 2 | Phosphoglycerol dihydroceramide (PGDHC) amplifies the level of amyloid precursor protein (APP) in lysates of CHO-7WD10 cells. CHO-7WD10 cells were stimulated with various concentrations of Pg-LPS (A, B) or PGDHC (C, D) for $48 \mathrm{~h}$ and lysates were then prepared and analyzed by Western blot. The signal quantification was carried out using Image J. ANOVA with Tukey's post-hoc test was used to evaluate the statistical significance. $\mathrm{N}=4$ samples/condition. ${ }^{\star *} \mathrm{p}<0.01,{ }^{\star * \star} \mathrm{p}<0.001$

C
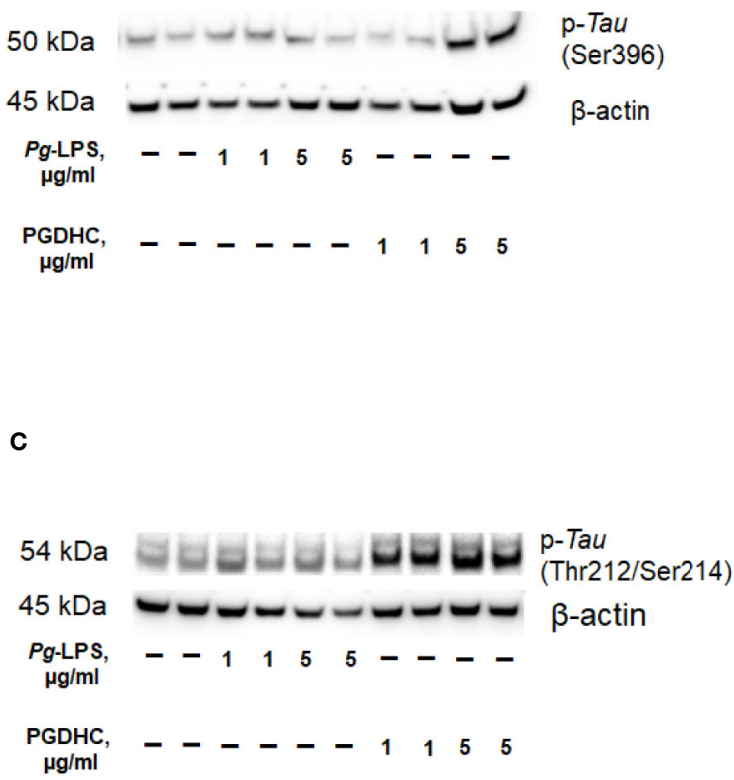

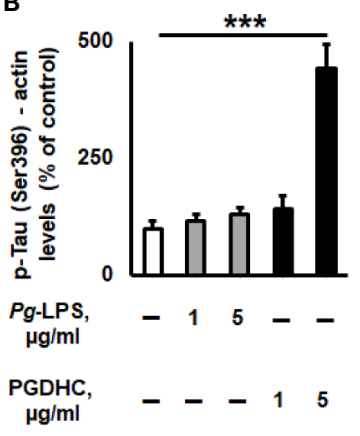

D

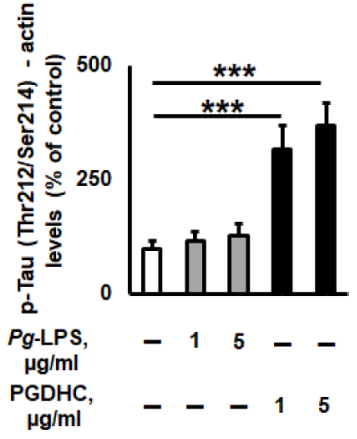

FIGURE 3 | The effects of phosphoglycerol dihydroceramide (PGDHC) and lipopolysaccharide (LPS) isolated from Porphyromonas gingivalis on hyperphosphorylation of tau protein in SH-SY-5Y cells in vitro. Representative images and quantification of tau phosphorylation at Ser396 (A, B) and Thr212/Ser214 (C, D) loci in SH-SY-5Y cells after exposure to P. gingivalis-LPS (Pg-LPS) and PGDHC for 48 h. Cell lysates were prepared and analyzed by Western blot. Western blot signal quantification was done using Image J. ANOVA with Tukey's post-hoc test was used to evaluate the statistical significance. $\mathrm{n}=4$ samples/condition. ${ }^{\star * \star} \mathrm{p}<0.001$ 
play an important role in the hyperphosphorylation of Tau protein, in addition to enhancing the secretion of $\mathrm{A} \beta$.

\section{PGDHC Promotes the Development of Senescence-Associated Secretory Phenotype in SH-SY-5Y Cells}

Since the cellular senescence of neurons is tightly connected with $\mathrm{AD}$ pathogenesis as well as other neurodegenerative diseases (27, 28), we next examined whether PGDHC or Pg-LPS elevated expression of some senescence-associated secretory phenotype (SASP) factors, including $\beta$-galactosidase, cathepsin B (CtsB) cysteine, and TNF- $\alpha$ and IL- 6 pro-inflammatory cytokines in SH-SY5Y cells in vitro. We observed that exposure of SH-SY-5Y cells to $P g$-LPS and PGDHC, both significantly elevated activity of senescence-associated $\beta$-galactosidase (Figures $4 \mathrm{~A}, \mathrm{~B}$ ) and CtsB (Figures 4B, C) compared with control cells. Further, expression patterns of pro-inflammatory TNF- $\alpha$ and IL- 6 mRNAs were also significantly elevated in response to $P g$-LPS and PGDHC (Figures 4D, E). On the other hand, expression of a senescence protection marker, sirtuin-1 (Sirt-1) was significantly diminished in SH-SY$5 Y$ cells in response to $P$. gingivalis-derived PGDHC and $P g$-LPS (Figures 5A, B). Therefore, these results indicate that persistent exposure of neurons to either PGDHC or Pg-LPS may induce phenotypes reminiscent of cellular senescence.

\section{DISCUSSION}

In this study, we aimed to examine the potential impact of phosphoglycerol dihydroceramide (PGDHC) isolated from the periodontal pathogen Porphyromonas gingivalis on the key features of $\mathrm{AD}$ pathogenesis, including amyloidogenesis, phosphorylation of tau protein, and cellular senescence, using in vitro models of $\mathrm{AD}$. To the best of our knowledge, this is the first study reporting that PGDHC
A

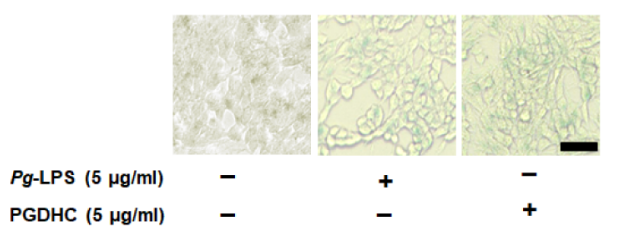

C

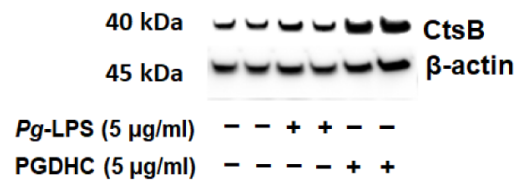

E

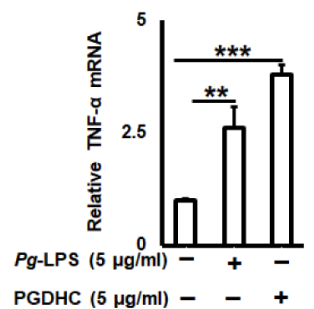

B

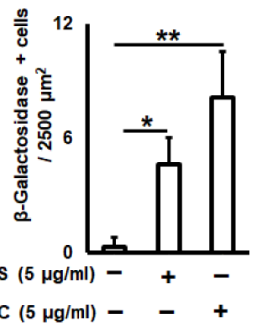

D
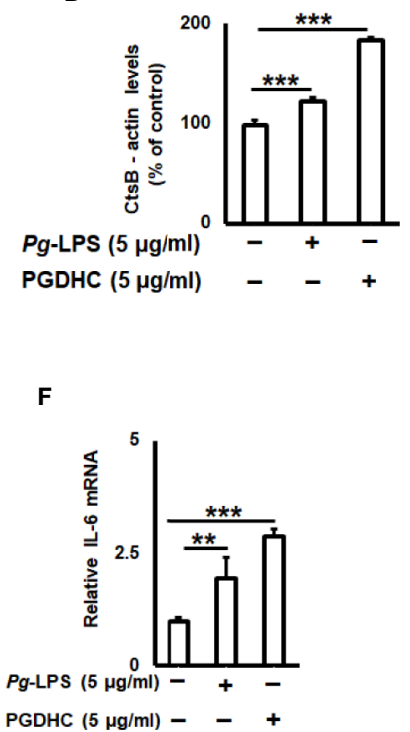

FIGURE 4 | Quantification of senescence-associated secretory phenotype (SASP) factors on P. gingivalis-LPS (Pg-LPS) and phosphoglycerol dihydroceramide (PGDHC)-stimulated SH-SY-5Y cells in vitro. Representative images (A) and quantification (B) of $\beta$-galactosidase activity. The number of blue $\beta$-galactosidase positive senescent cells was quantified microscopically. Scale bar is $50 \mu \mathrm{m}$. Representative signals (C) and quantification (D) of cathepsin B. Expression patterns of TNF-a (E) and IL-6 (F) mRNAs in SH-SY-5Y cells exposed to Pg-LPS and PGDHC. ANOVA with Tukey's post-hoc test was used to evaluate the statistical significance. $\mathrm{N}=4$ samples/condition. ${ }^{*} \mathrm{p}<0.05,{ }^{* *} \mathrm{p}<0.01,{ }^{* \star *} \mathrm{p}<0.001$. 
significantly upregulates amyloidogenesis in CHO-7WD10 cells. Our results also indicate that PGDHC elevates tau phosphorylation and expression of senescence-associated phenotype (SASP) factors in $\mathrm{SH}$ SY-5Y neuronal cells in vitro.

Accumulating lines of evidence support the conclusion that ceramide sphingolipids are important structural and bioactive signaling molecules in mammalian cells, with significant roles in the regulation of cell apoptosis, senescence, and autophagy, leading to the development of AD pathogenesis as well as other age-related neurodegenerative disorders $(29,30)$. On the other hand, it was reported that a limited number of human gut and oral bacteria belonging to Bacteroidetes phylum are also able to produce dihydroceramides that upregulate intracellular host ceramide levels $(23,31)$. Further, bacterial-derived sphingolipids have been shown to signal via inflammation-related pathways in colon and gingival tissues $(23,24,32)$. Important to this study, the gut Bacteroidetes species were detected at higher levels in $\mathrm{AD}$ patients compared to healthy controls (33). However, the role of dihydroceramides produced by oral Bacteroides spp. bacteria in the pathogenesis of $\mathrm{AD}$ has not been evaluated.

To date, unique dihydroceramides with non-mammalian structure, termed PGDHC and PEDHC, have been detected in three oral Gram-negative bacterial species associated with chronic periodontal disease, including Porphyromonas gingivalis, Tannerella forsythia, and Prevotella intermedia (24). These periodontal pathogens also produce several virulence factors, including LPS, gingipain, and lipids, which promote tissue inflammation, loss of connective tissue attachment, and bone loss $(34,35)$. It is important to mention that a recently published observation suggested that $P$. gingivalis-derived dihydroceramides are critical to the long-term persistence and presentation of other virulence factors, such as gingipains and polysaccharides (36).

Among periodontal bacteria species, $P$. gingivalis and its virulence factors were identified as significant risk factors for developing $\mathrm{AD}$ hallmarks $(15,37,38)$. Increasing genetic, biochemical, and pathological evidence strongly implies that both amyloidogenesis and tauopathy play a crucial pathological role in brains of $\mathrm{AD}$ patients (25). It is commonly accepted that amyloidogenesis is associated with the production of $A \beta$ peptides from its precursor protein APP by the consecutive actions of $\beta$ and $\gamma$-secretases, while tauopathy shows hyper-phosphorylation of tau protein in the brain of AD patients (39). A previous study reported that enhanced levels of intracellular mammalian ceramides directly affect the accumulation of $A \beta$ peptides and $\mathrm{p}$-Tau in vitro as well as in vivo (30). Here, we demonstrated that $P$. gingivalis-derived PGDHC increased the expression of APP protein and production of soluble $A \beta 42$ peptide in $\mathrm{CHO} 7 \mathrm{~W} 10$ cells (Figure 1) as well as hyperphosphorylation of tau protein in SH-5Y-SY cells in vitro (Figure 2), indicating a potential contribution of oral bacterial-derived dihydroceramides in amyloidogenesis and tauopathy. By contrast, we observed no or minimal effects of ultrapure $P g$-LPS on the release of soluble $A \beta$, and tau phosphorylation. These data contradict with earlier reports indicating that $P g$-LPS promoted accumulation of A $\beta$ and $\mathrm{p}$-Tau in vitro as well as in the brains of young and mid-age APP-transgenic mice and their wild type (37, 40-42).

Besides the role of $\mathrm{A} \beta$ and $\mathrm{p}$-Tau in the $\mathrm{AD}$ pathogenesis, a relationship between cellular senescence and $\mathrm{AD}$ may represent an additional hallmark in the context of aging $(27,43)$. More specifically, several groups have highlighted the potential beneficial effects of eliminating senescent cells on the $\mathrm{AD}$ associated neurodegeneration (44-46). It was also demonstrated that elevated activities of lysosomal $\beta$-galactosidase and neurodegenerative cathepsin $\mathrm{B}$ (CtsB) as well as secretion of various pro-inflammatory cytokines, including tumor necrosis factor- $\alpha$ (TNF- $\alpha$ ), interleukin-6 (IL-6), collectively termed as senescence-associated secretory phenotype (SASP) factors, directly correlate with cellular senescence and aging (47). Findings from our study also confirmed that both PGDHC and $P g$-LPS exacerbate the activity of senescence-associated $\beta$ galactosidase as well as the levels of CtsB protein in SH-SY-5Y cells in vitro (Figure 4). In addition, we also demonstrated that PGDHC and $P g$-LPS upregulated the expression of proinflammatory TNF- $\alpha$ and IL-6, suggesting the possible impact of $P$. gingivalis-derived virulence factors on the promotion of neuronal senescence (Figure 4). These data agree with earlier published observations indicating that LPS isolated from $P$. gingvalis induces premature cellular senescence (48) as well as promotes
A

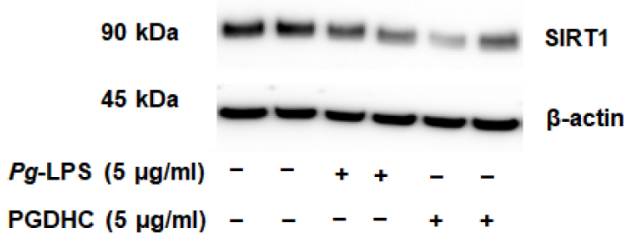

B

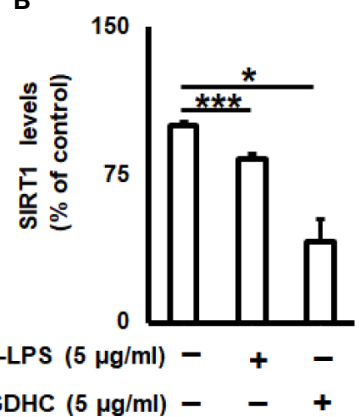

FIGURE 5 | Porphyromonas gingivalis-derived phosphoglycerol dihydroceramide (PGDHC) abrogates expression of the senesce-protection sirtuin-1 (Sirt-1) in SHSY-5Y cells in vitro. SH-SY-5Y cells were exposed either to Pg-LPS or PGDHC for $48 \mathrm{~h}$ and then the levels of Sirt-1 were evaluated by Western blot (A, B). ANOVA with Tukey's posthoc test was used to evaluate the statistical significance. $N=4$ samples/condition. ${ }^{*} p<0.05,{ }^{* \star *} p<0.001$. 
development of $\mathrm{AD}$-like phenotypes in mice via a CtsB-dependent manner (42). Also, the pathological role of mammalian ceramides in the promotion of cellular senescence and aging has been well documented (49).

While earlier studies reported that elevated production of SASPs contributes to the AD pathology, it was suggested that the age-protection $\mathrm{NAD}^{+}$-dependent sirtuin enzymes display beneficial effects in aging-related disorders, including $\mathrm{AD}$ (50). A positive correlation between Sirtl activity and reduction of $A \beta$ plaques and tauopathies was established in various animal models of AD (51-54). Here, we also confirmed that PGDHC as well as $\mathrm{Pg}$-LPS both diminished the amount of Sirt-1 protein in SH-SY$5 Y$ cells (Figure 5), indicating that $P$. gingivalis may downregulate the expression of aging protection markers in the human brain. Since elevated expression of Sirt-1 reduces cellular senescence, the potential effect of sirtuin agonists to abrogate the negative effects of $\mathrm{PGDHC}$ in the pathology of $\mathrm{AD}$ warrants further examination.

\section{CONCLUSION}

Collectively, the findings from this study indicate that PGDHC sphingolipid, isolated from the periodontal pathogen $P$. gingivalis, upregulated secretion of soluble $A \beta 42$ peptide and expression of APP in CHO-7WD10 cells. Moreover, elevated hyperphosphorylation of tau protein ( $\mathrm{p}$-Tau) was observed in human neuronal SH-SY-5Y cells in response to PGDHC. Furthermore, we found that PGDHC contributed to the cellular senescence of SH-SY-5Y cells via 1) production of SASP markers, including beta-galactosidase, cathepsin B (CtsB), and proinflammatory cytokines TNF- $\alpha$ and IL-6, and 2) downregulation of the senescence-protection marker sirtuin-1 (Sirt-1). Altogether, these data indicate that PGDHC may be a novel class of bacterialderived virulence factor for $\mathrm{AD}$, finding which lay the groundwork for future studies, evaluating the molecular mechanisms of $\mathrm{AD}$ pathology associated with periodontitis.

\section{REFERENCES}

1. Wimo A, Winblad B, Jonsson L. The worldwide societal costs of dementia: Estimates for 2009. Alzheimers Dement (2010) 6(2):98-103. doi: 10.1016/ j.jalz.2010.01.010

2. Wimo A, Guerchet M, Ali GC, Wu YT, Prina AM, Winblad B, et al. The worldwide costs of dementia 2015 and comparisons with 2010. Alzheimers Dement (2017) 13(1):1-7. doi: 10.1016/j.jalz.2016.07.150

3. Selkoe DJ. Alzheimer's disease: genes, proteins, and therapy. Physiol Rev (2001) 81(2):741-66. doi: 10.1152/physrev.2001.81.2.741

4. Qiu C, Kivipelto M, von Strauss E. Epidemiology of Alzheimer's disease: occurrence, determinants, and strategies toward intervention. Dialogues Clin Neurosci (2009) 11(2):111-28.

5. Corrada MM, Brookmeyer R, Paganini-Hill A, Berlau D, Kawas CH. Dementia incidence continues to increase with age in the oldest old: the 90 + study. Ann Neurol (2010) 67(1):114-21. doi: 10.1002/ana.21915

6. Cerovic M, Forloni G, Balducci C. Neuroinflammation and the Gut Microbiota: Possible Alternative Therapeutic Targets to Counteract Alzheimer's Disease? Front Aging Neurosci (2019) 11:284. doi: 10.3389/ fnagi.2019.00284

7. Paster BJ, Boches SK, Galvin JL, Ericson RE, Lau CN, Levanos VA, et al. Bacterial diversity in human subgingival plaque. J Bacteriol (2001) 183 (12):3770-83. doi: 10.1128/JB.183.12.3770-3783.2001

\section{DATA AVAILABILITY STATEMENT}

The raw data supporting the conclusions of this article will be made available by the authors, without undue reservation.

\section{AUTHOR CONTRIBUTIONS}

$\mathrm{AM}$ and ML contributed to the conception, design of the study, and wrote the manuscript. $\mathrm{CY}, \mathrm{AH}, \mathrm{JA}$, and $\mathrm{CR}$ performed all the experiments. RD, TK, and FN wrote sections of the manuscript. All authors contributed to the article and approved the submitted version.

\section{FUNDING}

This work was supported by a Nova Southeastern University President Faculty Research Development Grant and NIH Grants R01AG-064003, K02AG-068595, R03DE-027153, R15DE-028699 (AM), R01DE-209709 (TK), and R01DE-027642 (FN).

\section{ACKNOWLEDGMENTS}

The authors would like to thank Dr. Alireza Heidari and Ms. Nicole DeLorenzo for their excellent technical assistance.

\section{SUPPLEMENTARY MATERIAL}

The Supplementary Material for this article can be found online at: https://www.frontiersin.org/articles/10.3389/fimmu.2020. 591571/full\#supplementary-material

8. Ozmeric N, Preus NR, Olsen I. Genetic diversity of Porphyromonas gingivalis and its possible importance to pathogenicity. Acta Odontol Scand (2000) 58 (4):183-7. doi: 10.1080/000163500429190

9. Holt SC, Ebersole JL. Porphyromonas gingivalis, Treponema denticola, and Tannerella forsythia: the "red complex", a prototype polybacterial pathogenic consortium in periodontitis. Periodontol 2000 (2005) 38:72-122. doi: 10.1111/ j.1600-0757.2005.00113.x

10. Wu Y, Dong G, Xiao W, Xiao E, Miao F, Syverson A, et al. Effect of Aging on Periodontal Inflammation, Microbial Colonization, and Disease Susceptibility. J Dent Res (2016) 95(4):460-6. doi: 10.1177/0022034515625962

11. Carter CJ, France J, Crean S, Singhrao SK. The Porphyromonas gingivalis/ Host Interactome Shows Enrichment in GWASdb Genes Related to Alzheimer's Disease, Diabetes and Cardiovascular Diseases. Front Aging Neurosci (2017) 9:408. doi: 10.3389/fnagi.2017.00408

12. Riviere GR, Riviere KH, Smith KS. Molecular and immunological evidence of oral Treponema in the human brain and their association with Alzheimer's disease. Oral Microbiol Immunol (2002) 17(2):113-8. doi: 10.1046/j.0902-0055.2001.00100.x

13. Poole S, Singhrao SK, Kesavalu L, Curtis MA, Crean S. Determining the presence of periodontopathic virulence factors in short-term postmortem Alzheimer's disease brain tissue. J Alzheimers Dis (2013) 36(4):665-77. doi: 10.3233/JAD-121918

14. Kamer AR, Craig RG, Pirraglia E, Dasanayake AP, Norman RG, Boylan RJ, et al. TNF-alpha and antibodies to periodontal bacteria discriminate between 
Alzheimer's disease patients and normal subjects. J Neuroimmunol (2009) 216(12):92-7. doi: 10.1016/j.jneuroim.2009.08.013

15. Singhrao SK, Harding A, Poole S, Kesavalu L, Crean S. Porphyromonas gingivalis Periodontal Infection and Its Putative Links with Alzheimer's Disease. Mediators Inflammation (2015) 2015:137357. doi: 10.1155/2015/137357

16. Shaik-Dasthagirisaheb YB, Huang N, Weinberg EO, Shen SS, Genco CA, Gibson FC 3rd. Aging and contribution of MyD88 and TRIF to expression of TLR pathway-associated genes following stimulation with Porphyromonas gingivalis. J Periodontal Res (2015) 50(1):89-102. doi: 10.1111/jre.12185

17. Shaw AC, Panda A, Joshi SR, Qian F, Allore HG, Montgomery RR. Dysregulation of human Toll-like receptor function in aging. Ageing Res Rev (2011) 10(3):346-53. doi: 10.1016/j.arr.2010.10.007

18. Dunston CR, Griffiths HR. The effect of ageing on macrophage Toll-like receptor-mediated responses in the fight against pathogens. Clin Exp Immunol (2010) 161(3):407-16. doi: 10.1111/j.1365-2249.2010.04213.x

19. Akkaoui J, Yamada C, Duarte C, Ho A, Vardar-Sengul S, Kawai T, et al. Contribution of Porphyromonas gingivalis lipopolysaccharide to experimental periodontitis in relation to aging. Geroscience (2020). doi: 10.1007/s11357-02000258-1

20. Kanzaki H, Movila A, Kayal R, Napimoga MH, Egashira K, Dewhirst F, et al. Phosphoglycerol dihydroceramide, a distinctive ceramide produced by Porphyromonas gingivalis, promotes RANKL-induced osteoclastogenesis by acting on non-muscle myosin II-A (Myh9), an osteoclast cell fusion regulatory factor. Biochim Biophys Acta Mol Cell Biol Lipids (2017) 1862(5):452-62. doi: 10.1016/j.bbalip.2017.01.008

21. Filippov V, Song MA, Zhang K, Vinters HV, Tung S, Kirsch WM, et al. Increased ceramide in brains with Alzheimer's and other neurodegenerative diseases. J Alzheimers Dis (2012) 29(3):537-47. doi: 10.3233/JAD-2011-111202

22. Olsen I, Nichols FC. Are Sphingolipids and Serine Dipeptide Lipids Underestimated Virulence Factors of Porphyromonas gingivalis? Infect Immun (2018) 86(7):1-10. doi: 10.1128/IAI.00035-18

23. Johnson EL, Heaver SL, Waters JL, Kim BI, Bretin A, Goodman AL, et al. Sphingolipids produced by gut bacteria enter host metabolic pathways impacting ceramide levels. Nat Commun (2020) 11(1):2471. doi: 10.1038/ s41467-020-16274-w

24. Nichols FC, Yao X, Bajrami B, Downes J, Finegold SM, Knee E, et al. Phosphorylated dihydroceramides from common human bacteria are recovered in human tissues. PloS One (2011) 6(2):e16771. doi: 10.1371/journal.pone.0016771

25. Hardy J, Selkoe DJ. The amyloid hypothesis of Alzheimer's disease: progress and problems on the road to therapeutics. Science (2002) 297(5580):353-6. doi: $10.1126 /$ science. 1072994

26. Sze CI, Su M, Pugazhenthi S, Jambal P, Hsu LJ, Heath J, et al. Down-regulation of WW domain-containing oxidoreductase induces Tau phosphorylation in vitro. A potential role in Alzheimer's disease. J Biol Chem (2004) 279 (29):30498-506. doi: 10.1074/jbc.M401399200

27. Saez-Atienzar S, Masliah E. Cellular senescence and Alzheimer disease: the egg and the chicken scenario. Nat Rev Neurosci (2020) 21(8):433-44. doi: 10.1038/s41583-020-0325-z

28. Kritsilis M, Rizou SV, Koutsoudaki PN, Evangelou K, Gorgoulis VG, Papadopoulos D. Ageing, Cellular Senescence and Neurodegenerative Disease. Int J Mol Sci (2018) 19(10):1-37. doi: 10.3390/ijms19102937

29. Mielke MM, Bandaru VV, Haughey NJ, Xia J, Fried LP, Yasar S, et al. Serum ceramides increase the risk of Alzheimer disease: the Women's Health and Aging Study II. Neurology (2012) 79(7):633-41. doi: 10.1212/WNL.0b013e318264e380

30. Jazvinscak Jembrek M, Hof PR, Simic G. Ceramides in Alzheimer's Disease: Key Mediators of Neuronal Apoptosis Induced by Oxidative Stress and Abeta Accumulation. Oxid Med Cell Longev (2015) 2015:346783. doi: 10.1155/2015/ 346783

31. An D, Oh SF, Olszak T, Neves JF, Avci FY, Erturk-Hasdemir D, et al. Sphingolipids from a symbiotic microbe regulate homeostasis of host intestinal natural killer T cells. Cell (2014) 156(1-2):123-33. doi: 10.1016/j.cell.2013.11.042

32. Brown EM, Ke X, Hitchcock D, Jeanfavre S, Avila-Pacheco J, Nakata T, et al. Bacteroides-Derived Sphingolipids Are Critical for Maintaining Intestinal Homeostasis and Symbiosis. Cell Host Microbe (2019) 25(5):668-80.e7. doi: 10.1016/j.chom.2019.04.002

33. Vogt NM, Kerby RL, Dill-McFarland KA, Harding SJ, Merluzzi AP, Johnson SC, et al. Gut microbiome alterations in Alzheimer's disease. Sci Rep (2017) 7 (1):13537. doi: 10.1038/s41598-017-13601-y
34. Mysak J, Podzimek S, Sommerova P, Lyuya-Mi Y, Bartova J, Janatova T, et al. Porphyromonas gingivalis: major periodontopathic pathogen overview. J Immunol Res (2014) 2014:476068. doi: 10.1155/2014/476068

35. Jia L, Han N, Du J, Guo L, Luo Z, Liu Y. Pathogenesis of Important Virulence Factors of Porphyromonas gingivalis via Toll-Like Receptors. Front Cell Infect Microbiol (2019) 9:262. doi: 10.3389/fcimb.2019.00262

36. Moye ZD, Valiuskyte K, Dewhirst FE, Nichols FC, Davey ME. Synthesis of Sphingolipids Impacts Survival of Porphyromonas gingivalis and the Presentation of Surface Polysaccharides. Front Microbiol (2016) 7:1919. doi: 10.3389/fmicb.2016.01919

37. Dominy SS, Lynch C, Ermini F, Benedyk M, Marczyk A, Konradi A, et al. Porphyromonas gingivalis in Alzheimer's disease brains: Evidence for disease causation and treatment with small-molecule inhibitors. Sci $A d v$ (2019) 5(1): eaau3333. doi: 10.1126/sciadv.aau3333

38. Osorio C, Kanukuntla T, Diaz E, Jafri N, Cummings M, Sfera A. The Postamyloid Era in Alzheimer's Disease: Trust Your Gut Feeling. Front Aging Neurosci (2019) 11:143. doi: 10.3389/fnagi.2019.00143

39. De Strooper B, Annaert W. Proteolytic processing and cell biological functions of the amyloid precursor protein. J Cell Sci (2000) 113( Pt 11):1857-70.

40. Ishida N, Ishihara $\mathrm{Y}$, Ishida $\mathrm{K}$, Tada $\mathrm{H}$, Funaki-Kato $\mathrm{Y}$, Hagiwara $\mathrm{M}$, et al. Periodontitis induced by bacterial infection exacerbates features of Alzheimer's disease in transgenic mice. NPJ Aging Mech Dis (2017) 3:15. doi: 10.1038/s41514-017-0015-x

41. Ilievski V, Zuchowska PK, Green SJ, Toth PT, Ragozzino ME, Le K, et al. Chronic oral application of a periodontal pathogen results in brain inflammation, neurodegeneration and amyloid beta production in wild type mice. PloS One (2018) 13(10):e0204941. doi: 10.1371/journal.pone.0204941

42. Wu Z, Ni J, Liu Y, Teeling JL, Takayama F, Collcutt A, et al. Cathepsin B plays a critical role in inducing Alzheimer's disease-like phenotypes following chronic systemic exposure to lipopolysaccharide from Porphyromonas gingivalis in mice. Brain Behav Immun (2017) 65:350-61. doi: 10.1016/j.bbi.2017.06.002

43. Tiribuzi R, Orlacchio A, Crispoltoni L, Maiotti M, Zampolini M, De Angeliz M, et al. Lysosomal beta-galactosidase and beta-hexosaminidase activities correlate with clinical stages of dementia associated with Alzheimer's disease and type 2 diabetes mellitus. J Alzheimers Dis (2011) 24(4):785-97. doi: 10.3233/JAD-2011100525

44. Bussian TJ, Aziz A, Meyer CF, Swenson BL, van Deursen JM, Baker DJ. Clearance of senescent glial cells prevents tau-dependent pathology and cognitive decline. Nature (2018) 562(7728):578-82. doi: 10.1038/s41586-018-0543-y

45. Musi N, Valentine JM, Sickora KR, Baeuerle E, Thompson CS, Shen Q, et al. Tau protein aggregation is associated with cellular senescence in the brain. Aging Cell (2018) 17(6):e12840. doi: 10.1111/acel.12840

46. Zhang P, Kishimoto Y, Grammatikakis I, Gottimukkala K, Cutler RG, Zhang S, et al. Senolytic therapy alleviates Abeta-associated oligodendrocyte progenitor cell senescence and cognitive deficits in an Alzheimer's disease model. Nat Neurosci (2019) 22(5):719-28. doi: 10.1038/s41593-019-0372-9

47. Coppe JP, Desprez PY, Krtolica A, Campisi J. The senescence-associated secretory phenotype: the dark side of tumor suppression. Annu Rev Pathol (2010) 5:99-118. doi: 10.1146/annurev-pathol-121808-102144

48. Aquino-Martinez R, Rowsey JL, Fraser DG, Eckhardt BA, Khosla S, Farr JN, et al. LPS-induced premature osteocyte senescence: Implications in inflammatory alveolar bone loss and periodontal disease pathogenesis. Bone (2020) 132:115220. doi: 10.1016/j.bone.2019.115220

49. Trayssac M, Hannun YA, Obeid LM. Role of sphingolipids in senescence: implication in aging and age-related diseases. J Clin Invest (2018) 128 (7):2702-12. doi: 10.1172/JCI97949

50. Lalla R, Donmez G. The role of sirtuins in Alzheimer's disease. Front Aging Neurosci (2013) 5:16. doi: 10.3389/fnagi.2013.00016

51. Patel NV, Gordon MN, Connor KE, Good RA, Engelman RW, Mason J, et al. Caloric restriction attenuates Abeta-deposition in Alzheimer transgenic models. Neurobiol Aging (2005) 26(7):995-1000. doi: 10.1016/j.neurobiolaging.2004.09.014

52. Qin W, Chachich M, Lane M, Roth G, Bryant M, de Cabo R, et al. Calorie restriction attenuates Alzheimer's disease type brain amyloidosis in Squirrel monkeys (Saimiri sciureus). J Alzheimers Dis (2006) 10(4):417-22. doi: 10.3233/JAD-2006-10411

53. Kim D, Nguyen MD, Dobbin MM, Fischer A, Sananbenesi F, Rodgers JT, et al. SIRT1 deacetylase protects against neurodegeneration in models for Alzheimer's disease and amyotrophic lateral sclerosis. EMBO J (2007) 26 (13):3169-79. doi: 10.1038/sj.emboj.7601758 
54. Julien C, Tremblay C, Emond V, Lebbadi M, Salem N Jr., Bennett DA, et al. Sirtuin 1 reduction parallels the accumulation of tau in Alzheimer disease. J Neuropathol Exp Neurol (2009) 68(1):48-58. doi: 10.1097/NEN.0b013e3181922348

Conflict of Interest: The authors declare that the research was conducted in the absence of any commercial or financial relationships that could be construed as a potential conflict of interest.
Copyright (c) 2020 Yamada, Akkaoui, Ho, Duarte, Deth, Kawai, Nichols, Lakshmana and Movila. This is an open-access article distributed under the terms of the Creative Commons Attribution License (CC BY). The use, distribution or reproduction in other forums is permitted, provided the original author(s) and the copyright owner(s) are credited and that the original publication in this journal is cited, in accordance with accepted academic practice. No use, distribution or reproduction is permitted which does not comply with these terms. 